\title{
GÊNERO, HISTÓRIA E CULTURA NUMA SÓ TANGERINA
}

\author{
Andréa Andrade Prado* \\ Adriana Maria de Abreu Barbosa*
}

RESUMO: Este trabalho faz parte do processo de inventariar, à luz dos estudos de gênero, (BARBOSA, A, 2011) a obra de Rachel de Queiroz. De modo direto ou mais intimista, Rachel, dentro da história da literatura brasileira, foi uma mulher que rompeu barreiras através de sua vida, de sua escrita e de suas personagens. Ao revisar, revisitar, a historiografia literária, a crítica feminista instaura um novo modo de ver o mundo, sob a ótica da mulher. Analisamos aqui o conto Tangerine girl, publicado, pela primeira vez, em 1948. Dentre as diversas possibilidades que vislumbramos nesse conto, a autora nos aponta uma marcante personagem feminina, um contexto histórico em que a própria Rachel estava inserida e a "invasão" da cultura norte americana em terras nordestinas através da literatura, do cinema e da música.

PALAVRAS-CHAVE: Autoria Feminina; Crítica Feminista; Rachel de Queiroz.

"O estar no mundo é muito penoso. São apreensões, idas e vindas, inseguranças e incertezas: aquela sensação de estar permanentemente sob o fio da navalha." (Rachel de Queiroz, 2002)

\section{Para ler Rachel de Queiroz (ou à guisa de introdução)}

Escritora, jornalista, tradutora e dramaturga, Rachel de Queiroz foi a primeira mulher a ocupar uma cadeira dos imortais, na Academia Brasileira de Letras. Mas Rachel con-

\footnotetext{
* Mestranda do Programa de Pós-Graduação em Letras: Cultura, Educação e Linguagens, pela Universidade Estadual do Sudoeste da Bahia (Uesb).

** Doutora em Semiologia pela UFRJ (2001). Pós-doutora pelo Programa de Pós-graduação em Letras da Universidade Federal de Pernambuco (UFPE). Professora Titular da Universidade Estadual do Sudoeste da Bahia (Uesb), onde atua na graduação em Letras e nos Programas de Mestrado em Relações Étnicas e Contemporaneidade e em Letras: cultura, educação e linguagem.
} 
quistou muito mais. Foi destemida ao desbravar um universo permitido apenas aos homens. "É com Rachel de Queiroz na prosa da ficção, que a fala da mulher ingressou no campo social, abandonando os salões de chá para narrar a áspera tragédia da seca nordestina”. (BARROSO, 2008, p. 46)

Entretanto, não é a seca, e sim a mulher que se destaca em sua narrativa. Ela escreve sobre mulher, dá voz, poder, protagonismo à mulher. E é aí, sobretudo, que Rachel de Queiroz torna-se interessante à crítica feminista.

Como mulher consciente e sensível, comoveu-se com a condição feminina, sua natureza e conflitos, revelando em sua ficção vivências múltiplas [...] Suas personagens vivenciam diferentes situações, em diversas épocas e lugares, ainda que haja o predomínio da região nordestina, o que possibilita ao leitor descortinar um largo panorama da situação da mulher. (BARBOSA, M, 1999: p.17)

Resgatar a autoria feminina sob a perspectiva da crítica feminista continua sendo fundamental para uma possível correção de toda a história de exclusão da mulher/escritora e o seu merecido reconhecimento enquanto produtora ativa de conhecimento e cultura; e como afirma Heloísa Buarque de Hollanda (2016), Rachel é uma autora ainda insuficientemente explorada pela crítica literária.

A Desconstrução matou o autor, dando ao leitor toda a responsabilidade sobre a obra. Mas para os estudos de gênero é preciso sim ressaltar a autoria, particularmente a autoria feminina, dando voz e visibilidade a quem nunca as teve. "Ler um texto com seu gênero [...] é reivindicar para o texto a presença de sujeitos sociais nos dois polos: na produção e na recepção.” (BARBOSA, A, 2011: p.93)

Através do conto Tangerine girl, publicado em 1948, temos a oportunidade de vislumbrar importantes discussões suscitadas por uma mulher que, por meio da ficção, apresentou um momento histórico para o país, as transformações que o choque entre culturas acarretou e o papel atribuído e alcançado pela mulher em meio a esse processo.

O conceito de gênero aqui utilizado se baseia nas proposições de Tereza Laurettis (1994), onde gênero é um construção e não uma essência. Assim aplicado, esse conceito nos mostra como estava representado o modelo de mulher que se queria nos anos quarenta 
e cinquenta no Brasil do século XX, através de instituições como a família e o Estado; ou de outros aparelhos ideológicos como o cinema.

\section{Realidade ou ficção?}

Maria Luiza de Queiroz convenceu sua irmã Rachel de Queiroz a escrever uma biografia intitulada Tantos anos, em 1998. São memórias de ambas irmãs (Maria Luiza tornou-se coautora) que culminam numa breve história da vida de Rachel, onde se pode abstrair muito do seu processo de criação. É desse livro o relato abaixo. Da fascinação de Maria Luiza, e de outros tantos moradores da Fortaleza na década de 1940, que Rachel de Queiroz retirou o mote para o conto Tangerine girl.

Devo aos americanos, entretanto, uma das emoções mais fortes da minha vida. O dia tinha acabado de clarear quando chegou um dos moleques da casa, esbaforido, cinzento de susto, dizendo que tinha uma coisa lá para os lados da base [...]. Corri, fui ver o que era. E lá estava ele, o blimp [...], adejando ao vento, prateado, luminoso, refletindo o sol da manhã. Subi num pé de cajueiro, ao pé da parede do açude, e lá fiquei, talvez horas, no medo de que aquela visão fosse uma miragem, podendo, portanto, desaparecer a qualquer momento. (QUEIROZ \& QUEIROZ, 2010: p.152)

Diante da situação financeira e da insistência de compradores, seu Daniel Queiroz, pai de Rachel, vendeu uma parte do sítio que moravam, em Fortaleza, o Pici. Eram os anos quarenta, e pouco depois dessa negociação o Brasil entrou na Segunda Guerra Mundial, então os Queiroz descobriram qual seria a utilidade daquela e de outras terras ao redor: serviriam para a construção de uma base militar. Logo, engenheiros, técnicos, soldados e intérpretes circulavam pelo Pici "alegando a necessidade de conhecer as vizinhanças da base, a direção dos ventos e das águas; mas, na verdade, faziam um mapeamento de toda a região”(QUEIROZ \& QUEIROZ, 2010: p.150)

É válido ressaltar a importância que o Pici teve na vida de Rachel, sempre sensível a tudo e todos que a cercavam. Foi lá que viveu parte de sua adolescência, escreveu $O$ 
Quinze, perdeu o pai e dois irmãos, e viu a Guerra modificar tudo. "A ficção funciona assim, você não sai da sua origem, não importa onde você esteja"1.

Durante alguns anos, na Segunda Guerra Mundial, a marinha norte-americana instalou bases de observação no litoral norte do Brasil. A história do Tangerine girl se passa próxima a uma dessas bases quando uma "mocinha de cabelo ruivo" vai ao quintal, tendo à sua frente um laranjal, sacudir da toalha de mesa as migalhas de pão que restaram do café da manhã e um dos tripulantes do $b l i m p^{2}$, que sobrevoava a área, achou que na verdade ela lhe acenava, então, atirou-lhe uma caneca em sinal de agradecimento.

Nos dias seguintes, a cada voo, novos presentes eram lançados e a moça se apaixonava pelo marinheiro que não conhecia de perto, mas fantasiava diversos rostos. Entretanto, não era apenas um, mas vários marinheiros a dirigir o blimp, transformando entre eles a história da "menina do laranjal", a tangerine-girl, em uma bem vinda distração. Apenas quando eles marcam um encontro é que a moça percebe o engano e foge, decepcionada.

Dentre as diversas possibilidades de análise que vislumbramos nesse conto, a autora nos aponta, através do seu olhar, uma marcante personagem feminina, um contexto histórico em que a própria Rachel vivia e a "invasão" da cultura norte americana em terras nordestinas por meio da literatura, do cinema e da música.

Rachel retrata esse momento histórico através de uma menina interiorana e sonhadora, tendo sua própria irmã como parte da inspiração.

Com essa história de blimp, Rachel escreveu uma crônica muito bonita chamada Tangerine girl, mas pecou pelo exagero na licença poética. Nesse tempo eu era apenas uma garota e, além disso, também não gostava dos americanos. Acontece que a boa ficção tem muito mais peso do que a modesta realidade, e o fato é que todo mundo acreditou no que ela contava. (QUEIROZ \& QUEIROZ, 2010: p.152)

\footnotetext{
${ }^{1}$ Rachel de Queiroz em Cadernos de Literatura Brasileira, Instituto Moreira Salles, 1997: p.36.

2 Tipo de dirigível não rígido, utilizado inicialmente pelos norte-americanos na Segunda Guerra. Atualmente são meios de divulgação comercial.
} 
O mal entendido que "irritou” Maria Luiza revela o poder da ficção em criar realidades.

Se para Maria Luiza, a ficção vale mais que os próprios fatos, para alguns historiadores, sobretudo os que trabalham com a História Social, a literatura é também um testemunho histórico. Cabe ao pesquisador compreender a historicidade que perpassa o texto.

O texto literário como documento da história ou a história como contexto que atribui significado ao texto literário são caminhos que podem colidir no congestionamento da mão única por onde enveredam. Neste sentido, reflexo, expressão, testemunho, articulação, influência e termos similares são o léxico que costuma vincular o texto literário ao que há de coletivo e social para aquém e para além de suas páginas. Aliás, a escolha de um ou de outro termo já implica não só menor ou maior grau do entrelaçamento postulado entre literatura e história, como também e sobretudo o modo como se postula tal entrelaçamento (MALLARD, 1995: p. 21).

Dessa interdisciplinaridade é possível abstrair do Tangerine girl alegorias sobre um momento singular da história do Brasil; sem pretensões de buscar verdades, pois sabemos que a literatura é apenas um ponto de vista. E aqui, nos interessa o ponto de vista da mulher Rachel, em meados dos anos de 1940, do século XX: "os americanos estabeleceram uma base lá perto [do Pici] e os blimps, os pequenos dirigíveis prateados, pousavam quase em cima da nossa casa” (QUEIROZ \& QUEIROZ, 2010: p.82).

A entrada dos Estados Unidos na Segunda Guerra Mundial, em 1941, ao lado dos chamados países Aliados - Inglaterra, França, União Soviética, entre outros -, provocou uma reorganização diplomática entre este país e o Brasil, que até então se encontrava neutro ao conflito.

Em 1942, os Estados Unidos, por necessitarem do apoio estratégico do Brasil, assinam com o governo Vargas os Acordos de Washington, assim selando um empréstimo financeiro para a modernização e implantação do projeto siderúrgico brasileiro, além da aquisição de material bélico. Esses acordos foram decisivos para a criação da Companhia Siderúrgica Nacional e da Companhia Vale do Rio Doce. Assim o Brasil assumiu o compromisso de fornecer minérios estratégicos e importantes à indústria bélica americana, borracha, e 
permitir aos norte-americanos a instalação de bases militares em Belém, Natal, Recife, Fernando de Noronha e Fortaleza. (PAULA, 2013: p.01)

Em Fortaleza, entre 1943 e 1946, estima-se que cerca de cinquenta mil soldados norte-americanos circularam pela cidade, a pé, de jipe, avião ou nos blimps.

A presença dos norte-americanos mudou a rotina da população, como afirma Maria Luiza: "Para o nosso pessoal - nós todos, os nativos -, os americanos eram uma espécie de extraterrestres, tão diferentes, tão altos, louros na maioria, mas principalmente, de difícil comunicação”. (QUEIROZ \& QUEIROZ, 2010: p.151) Muitos nem mesmo gostavam da presença daqueles “intrusos”. A própria Maria Luiza afirma que não gostava dos estrangeiros. Antipatia que só aumentou com as transformações provocadas pela base aérea na região onde moravam. Ocupações desordenadas dos terrenos, comércio precário, desmatamento, roubos, levaram a “decadência do Pici” e a família Queiroz acabou vendendo todo o resto do sítio que ainda ocupavam.

\section{American way of life, guerra e romance na escrita de Rachel}

Em Tangerine girl vemos que uma marcante presença estrangeira imposta ao moradores de Fortaleza era o reflexo do que vinha acontecendo em quase toda a América Latina desde o fim da Primeira Guerra Mundial, quando os Estados Unidos saíram fortalecidos e passaram a estabelecer formas de intervenção nos países vizinhos, que se assemelhavam às práticas de colonização europeia dos séculos passados.

Se o espaço aéreo brasileiro estava se abrindo à penetração estrangeira, mais precisamente à Marinha Americana, simbolicamente o imaginário do cidadão brasileiro também passa a ser exposto a outras formas de organização e de imaginação da vida social. (SCHNEIDER, 2010: p.118)

Era o estilo de vida americano, o american way of life, que se espalhava por terras cearenses - e brasileiras -, através da língua, dos filmes, músicas, programas de rádio, comidas, bebidas e soldados. Tudo isso revelado no conto através da garota de cabelos ruivos. 
"Pôs-se a estudar com mais afinco o seu livro de conversação inglesa; quando ia ao cinema, prestava uma atenção intensa aos diálogos, a fim de lhes apanhar não só o sentido, mas a pronúncia” (QUEIROZ, 1997: p.48).

Inicialmente, à menina só interessou admirar a beleza prateada do blimp sobrevoando seu território. Apenas quando o primeiro presente é atirado pelo marinheiro, uma caneca de louça, a relação de "amizade" se instala, "uma espécie de namoro de gavião com gazela: ele, fero soldado cortando os ares; ela, pequena, medrosa, lá embaixo, vendo-o passar com os olhos fascinados" (QUEIROZ, 1997: p.48). Os presentes passam a ser lançados diariamente, um gorro, um lenço, revistas norte-americanas, mantendo a menina cada vez mais "presa" ao seu novo "amigo".

Rachel de Queiroz retirou também da realidade essa ideia dos presentes lançados, como relatou Maria Luiza: “[...] passavam em revoada pela nossa casa, a gôndola quase roçando a copa do pé de cedro, tão baixo que, de bordo, os rapazes acenavam e nos jogavam revistas e jornais americanos.” (QUEIROZ \& QUEIROZ, 2010: p.152)

Assim como a trocas de presentes serviram à aproximação entre europeus conquistadores e nativos ameríndios no período das Grandes Navegações, os presentes ofertados pelos soldados, seduziram Tangerine girl, levando-a a construir em seu imaginário a figura do "bom moço", gentil e educado que lhe oferecia presentes como forma atenção.

Os nativos ameríndios também se viram seduzidos por seus conquistadores ao receberem presentes, muitas vezes sem valor comercial, mas de grande valor simbólico. “[Cabral] ordenou que baixassem à terra e levassem aqueles dois homens, com seus arcos e flechas, mas isso depois que fizeram presentear a cada um deles com uma camisa, uma touca e um rosário [...]" (BUENO, 1998: p.97). Mal sabiam que estes presentes serviram apenas como um meio de ganhar sua confiança e em seguida lhe impor um ciclo de exploração e escravidão. Tangerine girl igualmente foi seduzida por presentes que levaram a uma realidade muito distante do que imaginava.

E não eram quaisquer presentes. Camisa, touca e rosário para os ameríndios aprenderem a vestir corpo e alma como os colonizadores. Caneca com as iniciais da marinha, 
gorro do aeronauta e revistas em inglês para a menina do laranjal aprender a lei e língua do neocolonizador.

Enfim, a figura do soldado americano, forte, viril e defensor da liberdade se revelou decepcionante e assustadora. Todavia, antes da decepção, é sabido que o encantamento dos nativos em relação aos conquistadores, reforçada pela prática de presentear, chegava ao extremo de leva-los a crer serem "deuses" vindos do além mar. Tangerine também "endeusou" o seu soldado, idealizando uma figura galante do cinema hollywoodiano:

Emprestava ao seu marinheiro as figuras de todos os galãs que via na tela, e sucessivamente ele era Clark Gable, Robert Taylor ou Cary Grant. [...] Juntos caminhariam até a base, depois dançariam um fox langoroso, ele lhe faria ao ouvido declarações de amor em inglês, encostando a face queimada de sol ao seu cabelo. (QUEIROZ, 1997: p.48)

Diversos elementos apresentados pelas telas de cinemas, músicas transmitidas via rádio, fotos e reportagens em revistas (como os exemplares da Life e da Time lançados para Tangerine) levavam a crer num ideal de democracia, progresso, trabalho e liberdade; superiores e inversos aos ideais das forças do Eixo - países liderados pela Alemanha. Entretanto, o que de fato interessava aos Estados Unidos era a expansão do seu mercado consumidor externo e para isso, uma "neocolonização" tornou-se necessária; o que acontece com Tangerine e seu território: “o aeronauta está ‘plantando’ sua cultura na terra que pertence à protagonista, exercendo um claro poder de influenciar, de cooptar, de seduzir e de, quem sabe, gerar novos frutos nesse solo estrangeiro”. (SCHNEIDER, 2010: p.121)

Ficção e realidade mais uma vez se misturam na escrita de Rachel. O Brasil, que até então tinha no francês seu modelo de civilização, com a chegada dos norte-americanos não será mais o mesmo, assim como a menina do laranjal após o contato com seu(s) aero$\operatorname{nauta}(\mathrm{s})$.

Se por um lado, a intervenção do capital estrangeiro e o american way of life cooptava e seduzia um parcela significativa da população brasileira, por outro, deixava as famílias tradicionais cada vez mais alertas quanto ao controle do comportamento de suas filhas, que 
viam perigo nas novidades que atraiam a juventude. "No cinema e na literatura, por exemplo, que apresentavam 'hábitos de países estrangeiros', tais como moças 'cheias de iniciativa', [...] comportamentos que 'nem mesmo nesses países devem ser aceitáveis"'. (PINSKY, 2014: p.54)

Carla Pinsky fez um apanhado das representações de masculino e feminino nos chamados Anos Dourados Brasileiros, de 1945 a 1964, a partir de publicações em revistas femininas da época, e sobretudo, as implicações dessas representações nas famílias de classe média urbana. Tangerine girl, se passa na gênese desse processo, em torno de 1943 e 1946, e por isso algumas observações de Pinsky são pertinentes a esta análise, como por exemplo, quando nos atemos aos "tipos" de moças apresentadas no conto: de um lado, as "pequenas" que os marinheiros "arranjavam" na cidade quando estavam de folga; do outro, as inocentes mocinhas representadas pela protagonista.

As "pequenas", citadas no conto, com quem os norte-americanos aprendiam, através de suas "bocas", "rudimentos de português", chamadas na vida real, em Fortaleza, de garotas Coca-Cola , foram consideradas "levianas", por desafiarem a moral da época, indo a lugares cheio de rapazes, namorando à noite nas areias das praias, entrando em cinemas e sorveterias abraçadas a soldados. Atitudes como estas "fazem parte das forças que promovem mudanças nas relações de gênero ao longo da história” (PINSKY, 2014: p.126)

Mas para Tangerine tal subversão ainda era impensável. Ela era "moça de família" e era preciso manter-se dentro de seus limites, evitando a todo custo ser taxada de "leviana", para ser aquela "que os homens procuram para esposa, fiéis, recatadas e puras" (PINSKY, 2014: p.58). O máximo de rebeldia que conseguiu atingir foi em devaneios e sonhos com o seu idealizado "aeronauta", o príncipe do imaginário coletivo patriarcal, salvador, que chegaria dos céus para resgatá-la.

\footnotetext{
${ }^{3}$ Esse nome se deve ao fato de ser a Coca Cola a bebida mais consumida naquele momento entre os norteamericanos, que trouxeram essa novidade para as terras cearenses.
} 
Aos olhos dos marinheiros, via-se uma garota que era apenas mais uma dentre as muitas que, deslumbradas com a presença dos norte-americanos, se divertiam em "orgias" nos bares e nas próprias bases militares.

Desde antes, ainda quando a viam apenas pela pequena janela do blimp, a comparação a uma atriz de sucesso no momento, representante das famosas pin-upst que tanto povoavam o imaginário masculino, os levaram ao apelido dado à menina:

Os marinheiros puseram-lhe o apelido de "Tangerine-Girl". Talvez por causa do filme de Dorothy Lamour, pois Dorothy Lamour é, para todas as forças armadas norte-americanas, o modelo do que devem ser as moças morenas da América do Sul e das ilhas do Pacífico. (QUEIROZ, 1997: p.48)

Lauretis (1994) apresenta-nos o cinema, "aparelho cinematográfico”, como tecnologia de gênero, onde a mulher muitas vezes é “objeto do olhar voyeurista do espectador" (p.221), através de imagens excessivamente sexualizadas e coisificadas nas telas. Por outro lado, para as espectadoras, os homens são a representação máxima de poder e virilidade. Então, "a sexualidade feminina tem sido invariavelmente definida tanto em oposição quanto em relação à masculina” (p.223).

Nesse jogo de poder, onde o masculino se sobrepõe ao feminino, o marinheiro em seu blimp conduz a performance em toda a ação.

O condutor do dirigível, abordando a jovem do alto, por cima, despejando objetos que possivelmente irão conquistá-la, reforçando os laços entre o que pertence à terra e o que pertence aos céus, tem o poder de dominar o campo da representação, influenciando mais do que sendo influenciado pelas visíveis diferenças entre as culturas envolvidas. (SCHNEIDER, 2010: p.121)

\footnotetext{
${ }^{4} \mathrm{O}$ termo surgiu entre as décadas de 40 e 50 para designar as imagens de mulheres com forte atrativo sensual que eram ilustradas em larga escala, fazendo parte assim do que conhecemos como cultura pop. Essas imagens seriam nada mais que ilustrações, pinturas ou fotografias de atrizes e modelos que representavam a época. As imagens eram usadas especificamente para revistas, cartazes, cartões postais e principalmente calendários, que foram muito utilizados por soldados na Segunda Guerra Mundial. Esses deixavam os calendários pendurados, por isso, o termo pin-up de pendurar em inglês.
} 
À Tangerine resta ser conduzida, pois "as mulheres vivem para o amor" e os homens para as coisas "práticas" e mais "importantes", como as guerras. Elas devem "amar pais, maridos e filhos independentemente do fato de serem ou não correspondidas de forma satisfatória. A abnegação faz parte do amor feminino” (PINSK, 2014: p.70).

\section{Considerações finais}

Elódia Xavier (1999) define a crítica feminista como sendo um "complexo de visões e práticas articuladas em torno de um ponto de vista comum: a contestação do patriarcado" (p.16). A história cultural e das mentalidades, a partir da década de 1960, reforçaram os estudos feministas, dando à mulher o lugar de agente, e não apenas vítima, denunciando as repetições que a afetam negativamente na sociedade.

$\mathrm{Na}$ literatura isso se mostrou latente, sobretudo quando ancorada em fatos históricos, muitas vezes levando o leitor a buscar elos com a realidade. Rachel de Queiroz apesar de negar qualquer filiação com movimentos feministas, desde sempre escreveu ficção com temas que tratam da questão feminina.

Em Tangerine Girl percebemos uma dose crítica à mulher que acredita no pacto patriarcal, no príncipe romantizado. Ao criar uma menina tola, Rachel revela mais uma vez seu olhar atento a realidade. Nem ela, nem sua irmã eram como a menina tangerina, menos ainda como as "garotas Coca-Cola", entretanto, sua atenção constantemente se voltava para o universo ao redor: "Muitas de minhas amigas viviam dramas assim. Tive sorte de crescer numa família mais aberta e descontraída. Mas o peso da opressão era uma tônica em grande parte das famílias que conheci” (NERY, 2002: p.111)

Dessa forma, nos sentimos autorizadas pela autora a ler sua obra sob uma perspectiva gendrada, isto é, marcada por especificidades de gênero, pois com critérios de leitura próprios, a crítica feminista "visa produzir um reconhecimento à cultura feminina" (BARBOSA, A, 2011: p.19). E em Rachel de Queiroz é possível, dentre muitas outras coisas, averiguar "conflitos existenciais vividos pelas personagens, à procura de superar os obstá- 
culos impostos por uma sociedade conservadora que as obriga a submeter-se às suas convenções, levando-as a negar seu próprio prazer e auto realização” (BARBOSA, M, 1999: p.16).

Com esse trabalho iniciamos nossa caminhada no universo ímpar criado por uma mulher impetuosa, independente, que não gostava de rótulos, nem de estereotipia, mas não se furtava à discussão, por vezes considerada contraditória, mas fiel a sua liberdade de pensamento: "Acho que a gente tem que dar o testemunho fiel do seu tempo e da sua gente e as conclusões que sejam tiradas ${ }^{5}$." E assim apoiadas tanto nas memórias como na ficção ficamos desejosas de saber mais sobre o que nos disse Rachel de Queiroz sobre mulheres da ficção e da realidade. Para isso, ficamos em escuta atenta e feminista aos textos e falas dela ${ }^{6}$.

\title{
GENDER, HISTORY AND CULTURE IN ONE TANGERINE
}

\begin{abstract}
This work is part of the process of inventing (BARBOSA, A, 2011) the work of Rachel de Queiroz in the light of gender studies. Directly or more intimately, Rachel, within the history of Brazilian literature, was a woman who broke barriers through her life, her writing and her characters. In reviewing, revisiting, literary historiography, feminist critique establishes a new way of seeing the world, from the point of view of women. We analyze the tale Tangerine Girl, published in 1948. Among the various possibilities we see in this tale, the author points out a remarkable feminine character, a historical context in which Rachel herself was inserted and the "invasion" of North American culture in lands northeastern regions through literature, cinema and music.
\end{abstract}

KEY WORDS: Female Authorship; Feminist Criticism; Rachel de Queiroz.

\section{REFERÊNCIAS}

BARBOSA, Adriana Maria de Abreu. Fiç̧ões do feminino. Vitória da Conquista: Edições UESB, 2011.

\footnotetext{
${ }^{5}$ Rachel de Queiroz no Programa de Televisão Roda Viva, em 01/07/1991. Disponível em: http://www.rodaviva.fapesp.br/materia_busca/407/Raquel $\% 20 \mathrm{de} \% 20$ Queiroz/entrevistados/rachel_de_queiroz_1991.htm

${ }^{6}$ Este artigo é parte de um projeto de Mestrado desenvolvido pelas autoras no Programa de Pós-graduação em Letras: Cultura, Educação e Linguagens - UESB.
} 
BARBOSA, Maria de Lourdes D. L. Protagonistas de Rachel de Queiroz: caminhos e descaminhos. São Paulo: Pontes, 1999.

BARROSO, Maria Alice. A mulher na literatura brasileira. In: Seminário de Literatura Brasileira - ensaios. Rio de Janeiro: UFRJ, 2008. Disponível em <http://www.poscritica.uneb.br/revistaponti/arquivos/volume2-n1/vol2n1-204-216.pdf. $>$ Acesso em: 05/09/2016.

BUENO, Eduardo. A viagem do descobrimento: a verdadeira história da expedição de Cabral. Rio de Janeiro: Objetiva, 1998.

GUERELLUS, Natália de Santanna. Rachel de Queiroz: mulher, escritora, personagem. ANPUH - XXV Simpósio Nacional de História - Fortaleza, 2009. Disponível em: <http://anais.anpuh.org/wp-content/uploads/mp/pdf/ANPUH.S25.0444.pdf>. Acesso em 30/08/2016.

HOLLANDA, Heloísa Buarque de. Rachel, Rachel \& mais Dona Fideralina de Lavras. Editora E-galáxia. Saraiva Reader, 2016.

LAURETIS, Teresa de. A tecnologia do gênero. In: HOLLANDA, Heloisa Buarque (org.). O feminismo como crítica da cultura. Rio de Janeiro: Rocco, 1994.

LOBO, Luiza. Guia de escritoras da literatura brasileira. Rio de Janeiro. EdUERJ, 2006.

MALLARD, Letícia. et. al. História Literatura - ensaios. Campinas: Unicamp: 1995.

NARVAZ, Martha Giudice \& KOLLER, Sílvia Helena. Metodologias feministas e estudos de gênero: articulando pesquisa, clínica e política. Maringá, v. 11, n. 3, p. 647-654, set./dez. 2006. Disponível em: <http://www.scielo.br/pdf/pe/v11n3/v11n3a20.pdf.> Acesso em $07 / 09 / 2016$.

NERY, Hermes Rodrigues. Presença de Rachel: conversas informais com a escritora. São Paulo: FUNPEC-Editora, 2002.

PAULA, Reverson Nascimento. Fortaleza em cotidiano: A instalação da base militar norte-americana e a alteração da rotina em terras alencarinas (1943-1945). 2013. Disponível em http:/ /www.snh2013.anpuh.org/resources/anais/27/1364928459_ARQUIVO_artigoanpuh2013.pdf. Acesso em 01/08/2017.

QUEIROZ, Rachel de. Tangerine Girl. In: O melhor das crônicas brasileiras. José Olympio Editora, Rio de Janeiro, 1997.

QUEIROZ, Rachel de \& QUEIROZ, Maria Luíza de. Tantos Anos. Rio de Janeiro: José Olympio, 2010.

SCOTT, Joan. História das Mulheres. In: BURKE, Peter: A escrita da história - tradução de Magda Lopes - São Paulo: Editora da Unesp, 1992. 
SCHNEIDER, Liane. Rachel de Queiroz e os norte-americanos: para que serve um dirigivel? Revista Diadorim, 2010. Vol.7. Disponível em https://revistas.ufrj.br/index.php/diadorim/article/view/3911. Acesso em 17/10/2017.

XAVIER, Elódia. Para além do Cânone. In: RAMALHO, Cristina. (org.) Literatura e feminino. Propostas teóricas e reflexões críticas. Rio de Janeiro: Elo, 1999.

Recebido em:

Aprovado em: 